\title{
Dynamic Production Management Architecture Considering Preparative Operation
}

\author{
Akira Tsumaya $^{1}$, Minoru Koike ${ }^{2}$, Hidefumi Wakamatsu ${ }^{1}$, Eiji Arai ${ }^{1}$ \\ 1 Osaka University, Graduate School of Engineering, \\ Yamadaoka 2-1, Suita, Osaka 565-0871, Japan, \\ WWW homepage: http://www6.mapse.eng.osaka-u.ac.jp/index-eng.html \\ 2 Collage of Industrial Technology, \\ Nishi-konyo 1-27-1, Amagasaki, Hyogo 661-0047, Japan,
}

\begin{abstract}
Automated factories have become complicated and need higher flexibility to satisfy various requirements today. In this environment, many concepts of autonomous \& distributed production systems have been proposed for a dynamic production management recently. In this paper, the preparative operations are discussed, that is focused on the decision of production process order with consideration of set-up time, and a dynamic production management architecture considering such preparative operations is proposed. First, the decision rule of the processing order by using production process information and real-time production system information is introduced. Then, we also pay attention to the combination and timing of processing sequences on both machining cells and parts in order to propose the timing rule and the set-up time rule referring to the real status of that are applied to be dynamic scheduling. Finally, real-time production-scheduling system using the proposed rules is developed, applied to a case study, and it is shown that the proposed system has the feasibility of the flexible correspondence against the disturbance.
\end{abstract}

\section{Introduction}

It is required for the production system to recognize a variety of turbulences, to make the action plan, and to modify the production plan promptly. It is difficult from both cost and time viewpoint to manage the whole system intensively in today's enlarged and complicated production systems. Therefore, the concept of autonomous \& distributed production systems has been proposed in recent years. Numerous intelligent and autonomous production systems, which are focused on product facilities and constructed intelligent system using network structure, have been proposed so far. By using the network system, each production facility can

Please use the following format when citing this chapter:

Tsumaya, A., Koike, M., Wakamatsu, H. and Arai, E., 2008, in IFIP International Federation for Information Processing, Volume 257, Lean Business Systems and Beyond, Tomasz Koch, ed.; (Boston: Springer), pp. 41-48. 
understand production status and can respond to the status. These methods are suitable to adopt an automated lot production factory [1-6]. However, most of such production systems work under the assumption that the production process in the factory is restricted to the result of process planning done beforehand while the distributed production system composed of some/many autonomous flexible machine cells does not need to fix the process beforehand. We think that higher flexibility can be realized with some degree of freedom in the order of production process. Integrated architecture that unites the process planning and production scheduling system is needed there.

On the other hand, in the lot production system, the production lot size is an important factor for productivity. A size is becoming smaller in recent years because a small lot size production is suitable in order to reduce the work-in-process inventory and to realize the higher flexibility. However, a small lot size has the disadvantage that the total set-up time is increased, and reducing set-up time is an important issue for introducing the small lot size. To solve this problem, in the process-planning phase, a lot based on group technology are widely introduced with the aim of reducing set-up time. However on production phase contains with various disturbances, it is still remained problem.

In this paper, a dynamic production management architecture considering preparative operations is proposed. We paid attention to two kinds of the preparative operations, that is focused on the decision of production process order and consideration of set-up time.

\section{Dynamic decision method of processing order}

The discrete production processes are usually expressed by arrow diagram. Generally, the only one optimum process that is not contradicted to arrow diagram is decided in the process-planning phase, and the master production schedule is constructed by using the decided process. However, the appropriate processing order may be possible depending on the real-time situation of the production system such as delay of one of a process or trouble of a machining cell. So, we assume that dynamic selection of appropriate processing order is useful for shortening the production tact time, and we also introduce the decision method of the processing order by using production process information and real-time production system information.

It is assumed here that the best one is selected as a dispatching rule from all candidates those can be done as next process. That is, the process that minimizes the following $P_{i j}$ is selected.

$$
P_{i j}=\left(V_{i} / a_{i j}+W_{i j}\right) /\left(\overline{V_{j}} / \overline{a_{j}}+\overline{W_{j}}\right)
$$

Here $a_{i j}$ is a processing ability for job $\mathrm{j}$ on machining cell $i . V_{j}$ is a volume of job $j$. $W_{i j}$ is a sum of the waiting and set-up time of job $j$ on machining cell $i . \overline{a_{j}}$ is a mean value of processing ability for job $j . \overline{V_{j}}$ is a mean volume of job $j . \overline{W_{j}}$ is mean value of waiting and set-up time of job $j$. This expression formula can be considered to be a relative SPT (Shortest Processing Time First) rule. 


\section{Consideration of set-up time}

In this section, we focused on the combination and timing of processing sequences referring to the real status of that is applied to the dynamic scheduling. For example, if the machining cell processes the same processing continuously, there are no need to change the neither machining tools nor jigs, so the tool exchange time is not needed. The on-line set-up that stops machine is classified into two types. One is the on-line set-up time without part (WOP set-up time) that can be done only with information of next processing part/product such as setting tool, setting jig, etc. The other is the on-line set-up that needs together with part (WP set-up) under the condition of finishing transportation process in order to deliver the part/product such as setting part/product, the positioning, etc. We further classified WOP set-up into three; the process depend on shapes of the part/product, the process depend on processing type of the part/product, and the process that cannot be skipped. WP setup is also further classified according to at what condition the operation can be omitted. Table 1 shows such classification of the set-up operation.

Table 1. Classification of set-up time

\begin{tabular}{|l|l|l|}
\hline $\begin{array}{l}\text { Type of on-line set-up } \\
\text { time }\end{array}$ & $\begin{array}{l}\text { Sub categories of set-up } \\
\text { operation }\end{array}$ & Set-up operation \\
\hline $\begin{array}{l}\text { On-line set-up without } \\
\text { part/product (WOP set- } \\
\text { up) }\end{array}$ & Depends on figure type & Setting jig(s), Remove Jig(s) \\
\cline { 2 - 3 } & Depends on processing type & Setting tool, Remove tool \\
\cline { 2 - 3 } $\begin{array}{l}\text { On-line set-up with } \\
\text { part/product (WP set- } \\
\text { up) }\end{array}$ & $\begin{array}{l}\text { Two continued processes are } \\
\text { done by same machining cell } \\
\text { with no change for attach }\end{array}$ & $\begin{array}{l}\text { Setting part/product, Remove } \\
\text { part/product }\end{array}$ \\
\cline { 2 - 3 } & Can not skipped operation & Position Setting \\
\hline
\end{tabular}

Then, we proposed timing rule and set-up time rule in selection and allocation, and adopted these classified set-up time to estimate the total processing time including the set-up time on each machine. If the shape type or the processing type of the continuous two processes on one machine is the same, WOP set-up time that depends on such type is skipped. WP type set-up can execute under satisfying following two conditions.

- $\quad$ Processing part/product has already delivered to the machine.

- $\quad$ WOP type set-up has been already finished.

Therefore, WP type set-up start time becomes later than transportation finishing time and WOP set-up finishing time. Figure 1 is an example of allocation process of the next process. On this case, machine 3, which is the fastest process finishing time of the next process, is selected to allocate as the next process. 


\begin{tabular}{|c|c|c|c|c|c|}
\hline Process finishing time & $10: 00$ & $10: 15$ & $10: 00$ & $10: 05$ & $10: 00$ \\
\hline Transportation time & $0 \mathrm{~min}$. & $9 \mathrm{~min}$. & $12 \mathrm{~min}$. & $15 \mathrm{~min}$. & $18 \mathrm{~min}$. \\
\hline Transportation finishing time & $10: 00$ & $10: 09$ & $10: 12$ & $10: 15$ & $10: 18$ \\
\hline WOP set-up time (figure) & $0 \mathrm{~min}$. & $6 \mathrm{~min}$. & $8 \mathrm{~min}$. & $0 \mathrm{~min}$. & $8 \mathrm{~min}$. \\
\hline WOP set-up time (processing) & $6 \mathrm{~min}$. & $0 \mathrm{~min}$. & $5 \mathrm{~min}$. & $0 \mathrm{~min}$. & $6 \mathrm{~min}$. \\
\hline WOP set-up time (need) & $3 \mathrm{~min}$. & $2 \mathrm{~min}$. & $2 \mathrm{~min}$. & $3 \mathrm{~min}$. & $3 \mathrm{~min}$. \\
\hline WOP set-up finishing time & $10: 09$ & $10: 23$ & $10: 25$ & $10: 08$ & $10: 17$ \\
\hline WP set-up start time & $10: 09$ & $10: 23$ & $10: 25$ & $10: 15$ & $10: 18$ \\
\hline WP set-up time (setting part) & $0 \mathrm{~min}$. & $6 \mathrm{~min}$. & $7 \mathrm{~min}$. & $6 \mathrm{~min}$. & $6 \mathrm{~min}$. \\
\hline WP set-up time (need) & $3 \mathrm{~min}$. & $3 \mathrm{~min}$. & $2 \mathrm{~min}$. & $2 \mathrm{~min}$. & $2 \mathrm{~min}$. \\
\hline Processing time & $35 \mathrm{~min}$. & $30 \mathrm{~min}$. & $25 \mathrm{~min}$. & $20 \mathrm{~min}$. & $20 \mathrm{~min}$. \\
\hline Process finishing time & $10: 47$ & $11: 02$ & $10: 58$ & $10: 43$ & $10: 46$ \\
\hline
\end{tabular}

Fig. 1. A decision example of allocation process

\section{Concept of parts \& packets unification system}

Recognizing the real-time status of both machining cells and parts/products are required for realizing the proposed approach. RFID technology is recently widely utilized and available from a practical viewpoint of cost, tip size and memory size Thus, we introduced parts \&packets unification system architecture [7, 8] here. The concept of a dynamic production scheduling system using parts and packets unified architecture is shown in Fig. 2. The read/write type IC tag is attached in the parts, and ID number and the present status are written in it. The IC tag attached on a unit transmits the real-time information of ID number, current position, and status through the network system whenever it passes through the gate provided in the factory.

The production planning system, by comparing with real-time information on each part with the master schedule, can detect the gap between the master schedule and the actual state. According to the gap, re-scheduling is performed.

Using this kind of architecture, the system can grasp real-time status of all facilities and parts/products. 


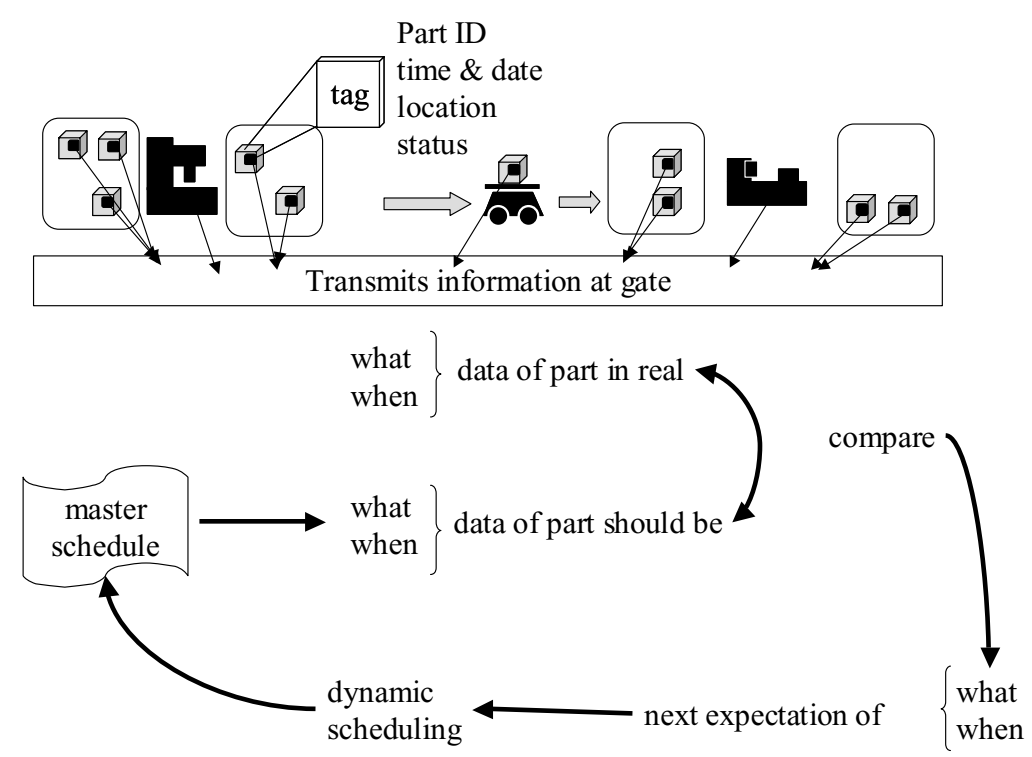

Fig. 2. The concept of dynamic production scheduling system using parts \& packets unified architecture

\section{Dynamic production scheduling system and application}

In this section, we explain a pilot system of production process in a factory, and show some results of case studies. The components of the system are shown in Fig. 3. This virtual factory example has following preconditions. Facilities of this factory are five machining cells, two AGVs, and storage. The initial value of machining ability on each machining cell is set up previously. Each part/product carried out from storage and made several jobs to be the complete product. It is assumed that the conveyance capability of two AGV is equal, and it moves in the orbit with one way. The scheduling system decides the allocation of the part to the cell according to the following procedures.

(1) A previous notice of the processing end time is notified from the processing cell to the scheduler at defined time before the finish processing.

(2) When the scheduler receives the notice, it sends part/product, which is almost finished on current job, a requirement of sending its next job information.

(3) Part/ product sends required information to the scheduler.

(4) The scheduler sends each processing cells the part/product 's shape and next processing type, and required calculation result of the set-up time and the processing time if the cell undertake the job. The scheduler also sends each AGV the part/product 's current position and finishing time of current process, and required calculation result of transportation finishing time on each machining cells. 
(5) Each machining cells sends required information to the scheduler; those are WOP set-up time, WP set-up time, and processing time. Each AGV sends required information, which are transportation-finishing time to each cells, to the scheduler.

(6) The scheduler uses these information to adopt the relative SPT scheduling rule, and decides allocation of the part/product to the cell.

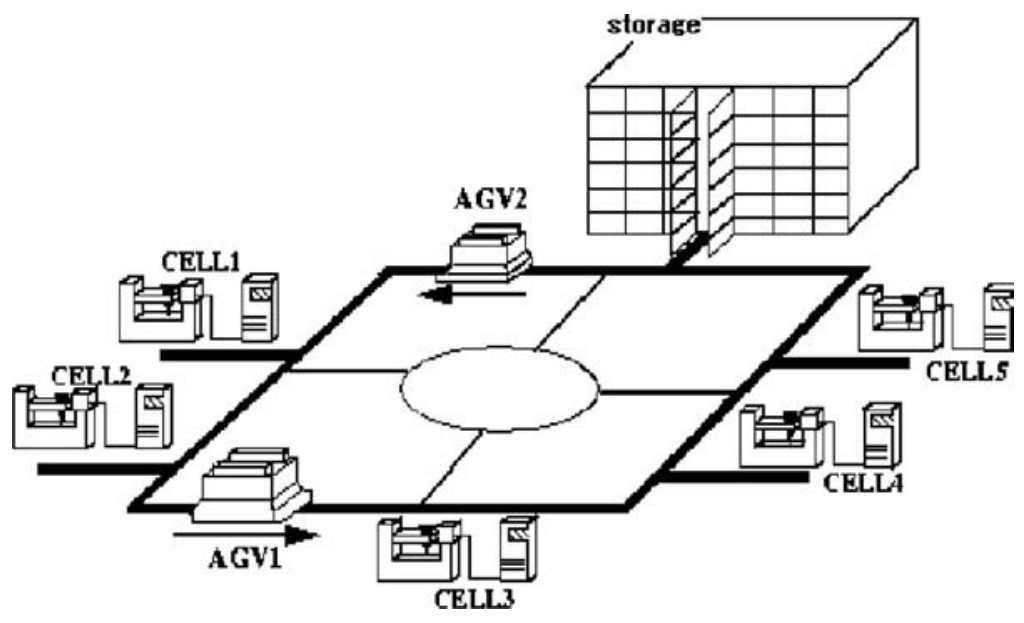

Fig. 3. The component of the system in a factory

Some virtual simulation was performed using the system. First, we compare proposed set-up time with constant set-up time. The Gantt chart of the simulation is shown in Fig. 4. As these results, the system introducing the proposed set-up time rules worked effectively to shorten the total production time. We also compare proposed dispatching rule with normal SPT dispatching rule. Figure 5 shows the Gantt chart of each simulation. These results suggest proposed dispatching rule is useful under each lot's processing status is recognized. Furthermore, we found the proposed dispatching rule becoming the most effective under the environment where the general-purpose machine tool exists together to a special purpose machine tool.

\section{Conclusion}

A real-time production scheduling architecture considering preparative operations is proposed. Decision method of production process order by using process order information and real-time production system information is introduced. Moreover, set-up time is analyzed in detail considering with the processing order for each machining cell, and proposed sequence timing and set-up time rules. Using the proposed rules, a pilot system is developed and applied to the case study. Although proposed production management architecture can realize local optimization of production schedule, not total optimization, the system worked effectively to shorten 
the total production time. The results also shows the proposed system has the feasibility of the flexible correspondence against the disturbances.

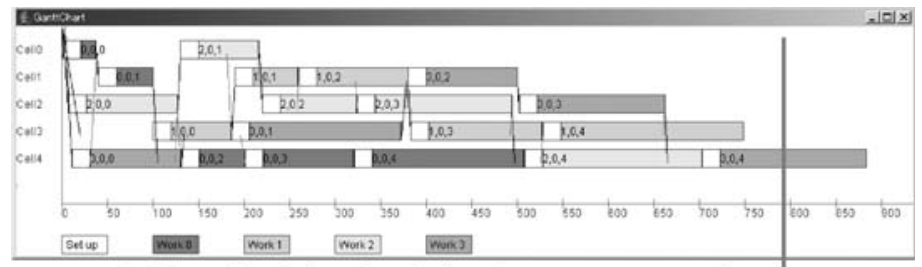

(a) Result of the simulation (constant set-up time

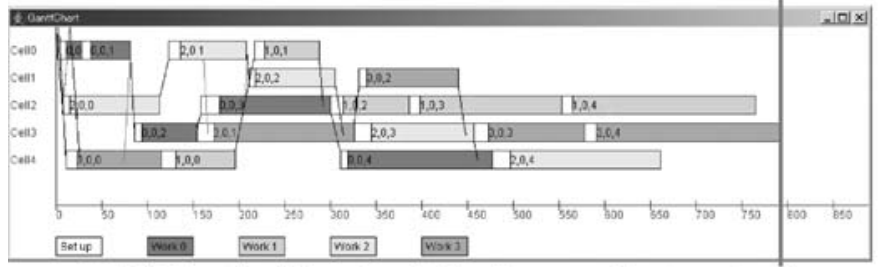

(a) Result of the simulation (proposed set-up time)

Fig. 4. The Gantt chart of the simulation (considering set-up time)

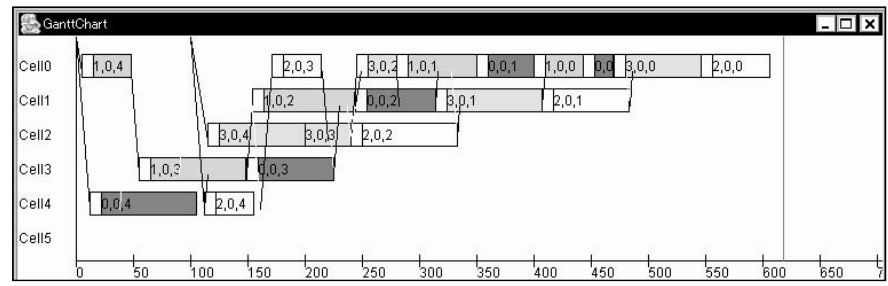

(a) Result of the simulation (SPT dispatching rule)

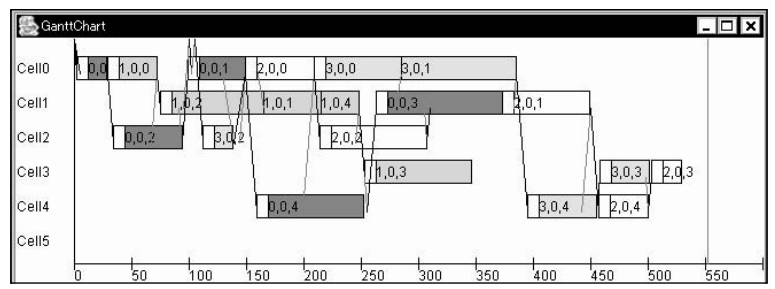

(b) Result of the simulation (proposed dispatching rule)

Fig. 5. The Gantt chart of the simulation (considering dispatching rule) 


\section{References}

1. Ueda, K. (1992). An Approach to Bionic Manufacturing Systems Based on DNAType Information, Proceedings of International Conference on Object-Oriented Manufacturing Systems, pp. 305-308.

2. Ranky, P.G. (1992). Intelligent Planning and Dynamic Scheduling of Flexible Manufacturing Cell and Systems, Proceedings of 1992 Japan-U.S.A. Symposium on Flexible Automation, pp. 415-422.

3. Wiendahl, H.P. and Garlichs, R. (1994). Decentral Production Scheduling of Assembly Systems with Genetic Algorithm, Annals of the CIRP, Vol. 43, No. 1, pp. 389-396.

4. Fujii. S., Kaihara. T., and Tanaka, M. (1999). A Distributed Virtual Factory in Agile Manufacturing Environment, Proc. 15th Conference of the International Foundation for Production Research, II, pp.1551-1554.

5. Sugimura, N., Tanimizu, Y., and Yoshioka, T. (1999). A Study on Object Oriented Modeling of Holonic Manufacturing System, Manufacturing System, Vol. 27, No. 3, pp. 253-258.

6. Shirase, K., Wakamatsu, H., Tsumaya, A., and Arai, E. (2005). Dynamic Cooperative Scheduling Based on HLA, Knowledge and Skill Chains in Engineering and Manufacturing - Information Infrastructure in the Era of Global Communications, Springer, pp.285-292.

7. Arai, E., Tsumaya, A., Watanabe, H., Wakamatsu, H., Shirase, K., and Takata, M. (2004). Dynamic Management Architecture for Production Systems Based on Parts and Packets Unification, Experiences from the Future - New Methods and Applications in Simulation for Production and Logistics, Fraunhofer IRB Verlag, pp.491-500.

8. Watanabe, H., Tsumaya, A., Wakamatsu, H., Shirase, K., and Arai, E. (2004). Dynamic Scheduling System with Variable Lot Size Approach Using Parts and Packets Unification, Proceedings of 2004 JAPAN-U.S.A. Symposium on Flexible Automation (JUSFA2004), CD-ROM, JS_038(4 pages). 